\title{
Principals OF DEVEloping THE UNDERWATER WALKING ROBOTS
}

\author{
Chernyshev, V.; Nechaev, A.; Petrakov, M.; Pryanichnikov, V. \& Prysev, E.
}
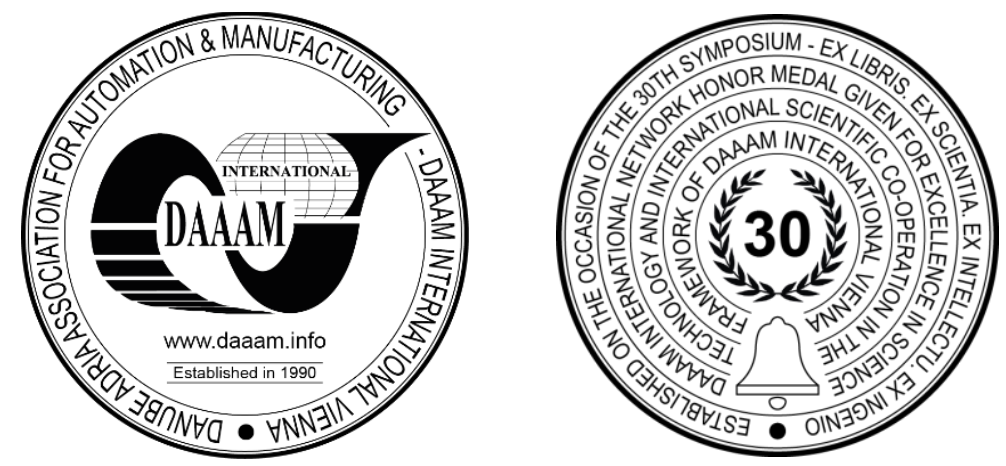

This Publication has to be referred as: Chernyshev, V[adim]; Nechaev, A[lexander]; Petrakov, M[axim]; Pryanichnikov, V[alentin] \& Prysev, E[vgeny] (2019). Principals of Developing the Underwater Walking Robots, Proceedings of the 30th DAAAM International Symposium, pp.1149-1151, B. Katalinic (Ed.), Published by DAAAM International, ISBN 978-3-902734-22-8, ISSN 1726-9679, Vienna, Austria

DOI: $10.2507 / 30$ th.daaam.proceedings.161

\begin{abstract}
We considering the creation of underwater walking robotic apparatus with satellites, the structure of such robotic complex and it's main subsystems. The whole complex is divided into components: central unit with supervising operator, welltraversed basic station, connected with the central unit by a cable and with fully autonomous and highly maneuverable robots (by ultrasonic channels), which are collecting information and directly performing underwater works. The key problem to realize the advantages of this complex is to realize the contactless method of charging the onboard batteries directly in the working area, without the need to be back to the surface and transfer the data to the base. The possibility of dividing the control channel into cable and hydroacoustic parts, as well as the use technical vision for control is also shown. More details are in the DAAAM Scientific book-2019.
\end{abstract}

Key words: Walking robotic complex with contactless power supply for underwater applications.

\section{Introduction}

The solution of a whole range of typical tasks and complex works on the sea bottom or near the bottom are currently entrusted to robots. We suggest of robotic complex (RC, fig.1) - underwater walking robotic apparatus with floating around satellite-robots and control unit for supervising operator. Main tested components of such RC are:

- the device providing walking motion both on the sea bottom and on any beach,

- navigation and control system, including the computer vision remote TV-system,

- information support system for robotic complex control,

- communication system with the supervisor, working on the central control unit,

- power supply devices for the underwater satellites (fig. 2).

- system of rapid transfer of large amounts of the accumulated information to the operator via basic walking station.

To perform a large list of underwater works, the effective structure of the hardware construction can be the representation of the entire system by three components. It is a central control unit CU with an supervising operator, a relatively sedentary unmanned base station RC connected to the CU by cable and fully autonomous highly maneuverable modules (AM) directly performing underwater work [5]. Such hardware construction of the robotic system gives a number of fundamental advantages and ultimately significantly expands the operational capabilities of the robotic complex [4]. With this arrangements, the robotic complex (RC) will combine the following systems. 


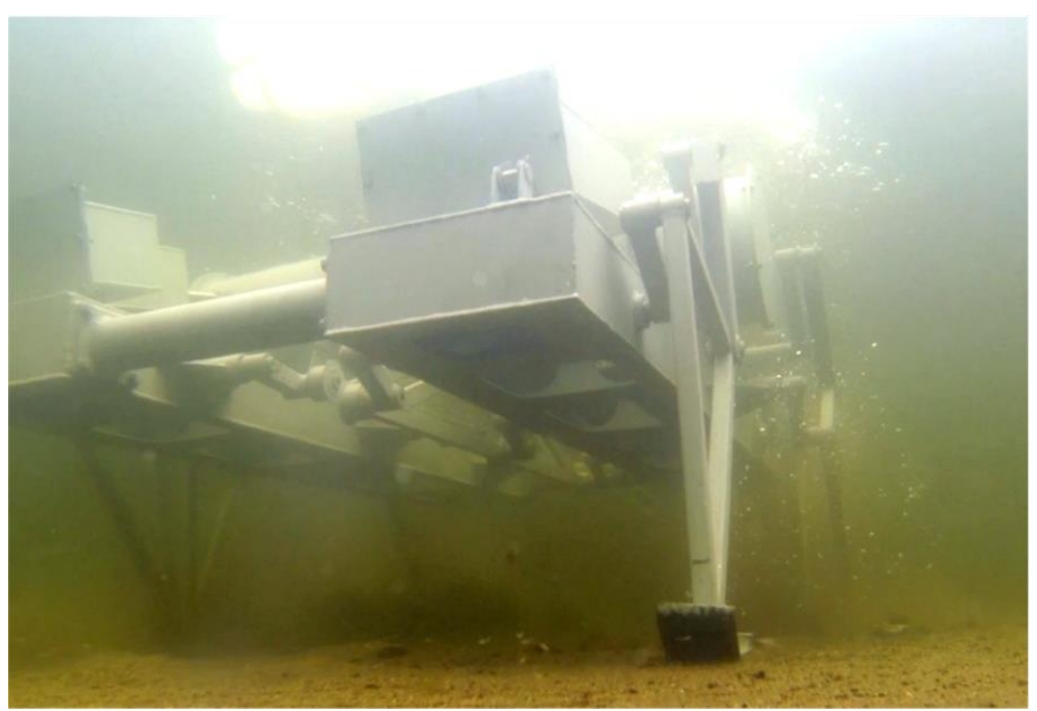

Fig.1. Implemented walking underwater robotic complex with contactless power supply for small robots-satellits.

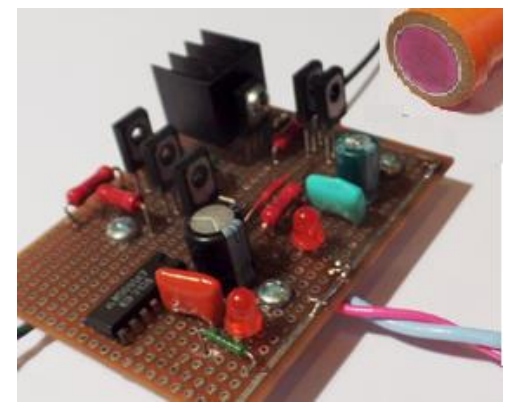

A. Ultra-shot signals ultrasonic generator for data transfer and sonar.

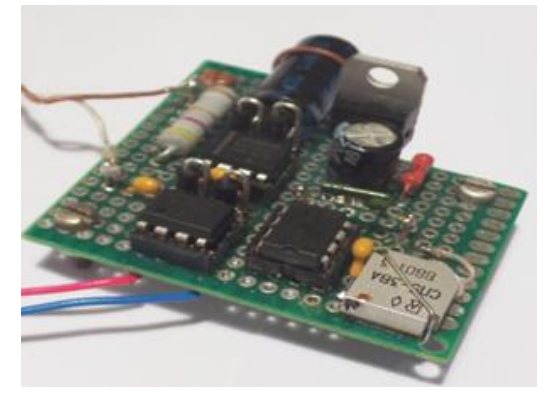

B. Master generator for contactless power supply.

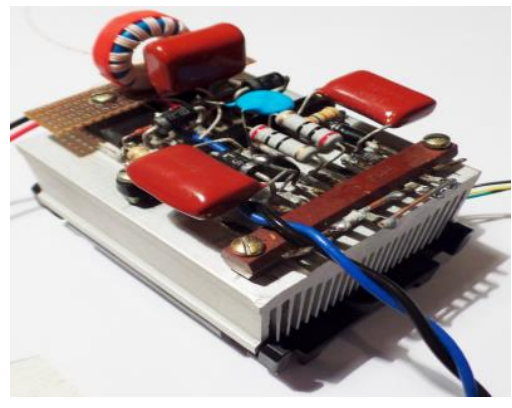

C. Increased power contactless power supply system.

Fig. 2. Main electronic components for robotic underwater complex.

\section{Navigation and control system for underwater apparatus}

For reliable delivery of the RC to the place of underwater works, the walking device was chosen, which has the best characteristics for overcoming obstacles on the sea bottom. The RC is connected to the control unit by a cable, thus the control is solved in traditional way: a TV cameras with floodlights are placed on board of the RC and the television monitor (or/and special 3D-projection system) for the operator is placed on the supporting boat. The delivery of RC to the working area is provided by 6-legged heavy vehicle with unique characteristics - maximum pulling force is $1.5-2$ times more, then its own weight. The installed navigation system depends on the tasks of the mission and have to provide orientation data and RC coordinates to the operator. It also includes an electronic compass, gyroscope etc.

\section{Information supporting system - main elements}

The RC can be equipped with the information supporting system according with the customers requirements. The system provides current data describing the bottom objects in the working area. We also use technical vision (TV), but it's restricted by the water transparency. Innovative technology of TV provides identification and analysis of objects, including the analysis of stereo images in the working area. This system is realized for two applications - for service robots AMUR-307 and for underwater conditions.

The TV was tested for the following tasks:

- system measuring the coordinates, angles and orientation of objects based on color analisies;

- measuring system with a video processor integrated into the television camera for high-precision measurement of coordinates.

Some of the results obtained:

- detecting the linear objects coordinates - not more, than 1/20000 of the field of view area and angular coordinates no more than 0.1 degrees;

- working frequency - from 30 to $120 \mathrm{~Hz}$;

- illumination available - from $10^{-4}$ Lux to $10^{+5}$ Lux;

- interface-Ethernet ( $1 \mathrm{~Gb} / \mathrm{s}), \mathrm{RS}-485 / 232$, USB. 
The main differences between the developed TV technologies are the combination of hardware and software for realtime image processing, high-precision (sub-pixel) measurements of spatial coordinates of moving objects, methods of training and recognition of complex scenes.

Taking into account the high probability of turbidity of the working area, in addition to the TV-cameras, robots were equipped with ultrasonic location devices (course and side view), including both receiving and transmitting equipment and microprocessors for primary processing of the receiving signals. Communication system with the operator of the central control unit is represented by a television channel over cable. Communication between autonomous modules and central unit is organized through walking base and ultrasonic channel with special coding, and then through the cable. On this channel is undertaken operational control and functional activity of autonomous robots. Power supply system of the underwater complex is as following. The primary source of electricity is placed on the shore. The customer can choose on-board ship network, or mobile power generator, or a powerful battery. Power supply for walking base as well as for AM transmitted through the logging cable. The power supply autonomous robots is organized from on-board batteries. Moreover, their periodic automatic recharging is made contactless from the base without surfacing, directly in the working area. For this purpose, radiating and receiving devices were developed and installed on the RC and AM respectively (fig.2).

\section{The transmission system for big data to the superviser}

To capture large amounts of information and the results of long observation is proposed to handle by contactless method over a radio channel in the range of 1-2 GHz. Of course that transmission range in salt water is limited to a few centimeters, but it's enough, as robou approaches the base. The significant attenuation of radio waves at ranges exceeding several centimeters completely eliminates the possibility of unauthorized acsess. In conclusion, the following implemented tasks were actually tested with positive results:

- design of walking robotic complex with electric drives and smooth speed control (it allowed to avoid obstacles both

on the sea bottom or on a seashore);

- architecture of software supervising control was realized via cable with TV-camera data transfer;

- non-contact re-charger for a on-board batteries of autonomous robots with high power was realized;

- it was done the information supporting system, based on ultrasonic sonars and data transfer;

- several variants of visual system for water and normal conditions were iplemented.

The full-scale tests the underwater robotic complex and the listed elements were done during the sea expeditions. It showed the efficiency of the proposed solutions for the realized robotic complex in offshore zone to search and pull from water various objects and then transporting them to the shore.

\section{References}

[1] V.V. Arykantsev, A. A. Ariskin, O.O. Belyaev, A.Ya. Ksenzenko, E.A.Prysev, V.E. Pryanichnikov, V.V. Chernyshev, S.R.Eprikov. Supervisory control of underwater walking apparatus, Extreme robotics and conversion trends. Collection of abstracts of the international scientific and technical conference, 2018, St. Petersburg, p. 203.

[2] A.Y. Ksenzenko, Yu.S. Marzanov, E.A. Prysev, V.E. Pryanichnikov, V.V. Chernyshev, Prototyping of contactless data exchange and power supply of underwater satellite robots with a base station walking on the bottom, Extreme robotics. Collection of abstracts of the international scientific and technical conference, 2017, St. Petersburg, p. 268.

[3] B. Katalinich, A. Y. Ksenzenko, S. V. Kuvshinov, Y. S. Marzanov, E. F. Prysev, V. E. Pryanichnikov, R. V. Helemendik, S. R. Eprikov, Development of distributed software and hardware robotariums. Extreme robotics. Proceedings of the international scientific and technical conference, 2016, St. Petersburg, pp. 460-465.

[4] V. E. Pryanichnikov, T. Bielich, O. I. Davydov, B. Katalinich, R. V. Helemendik, F. Ya. Ksenzenko, S. V. Kuvshinov, Yu. S. Marzanov, E. A. Prysev, D. Vitsan, A. Ugleshik. Intelligent robotics is a way of implementing sensor and control systems. Extreme robotics. Proceedings of the international scientific and technical conference, 2015, St. Petersburg, pp. 34-39.

[5] Bielich T., Ksenzenko A. Ya., Kirsanov K. B., Pryanichnikov V. E. Increasing the time of continuous operation of the underwater inspection robotic complex. "Information-measuring and control systems. 2015, No. 7, pp. 51-56.

[6] Ksenzenko A.Y, Prysev E.A., Pryanichnikov V.E., Chernyshev V.V., (2017). Intelligent Robotronics: Design the Contactlees Charger and Contactless Data transfer between underwater Robot-Satellits and Underwater 6-legged Vehicle. Proceedings of the 28th DAAAM International Symposium on Intelligent Manufacturing and Automation, pp. 1197-1201, B. Katalinic (Ed), Published by DAAAD International, ISBN 978-3-902734-08-2, ISSN 1726-9679, Vienna, Austria, DOI: 10.2507/28th.daaam.proceedings.166.

[7] Kebkal O., Kebkal V., Kebkal K., Evins. Framework for development of underwater acoustic sensor networks and positioning systems. Oceans, 2015, IEEE, Italy, 2015, pp 1-6. 